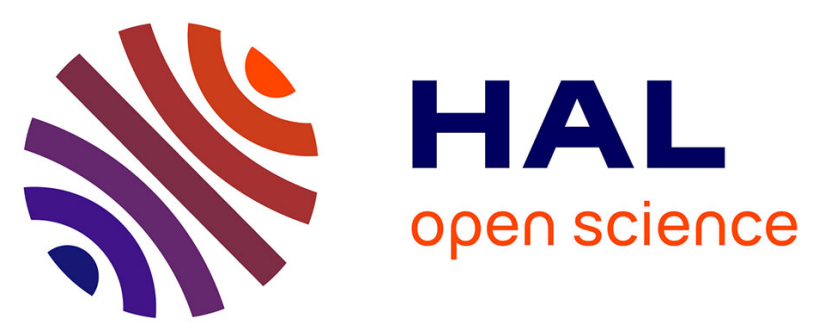

\title{
A study of pollution removal in exhaust gases from animal quartering centers by combining photocatalysis with surface discharge plasma: From pilot to industrial scale
}

Aymen Amine Assadi, Abdelkrim Bouzaza, Isabelle Soutrel, Philippe Petit, Karim Medimagh, Dominique Wolbert

\section{To cite this version:}

Aymen Amine Assadi, Abdelkrim Bouzaza, Isabelle Soutrel, Philippe Petit, Karim Medimagh, et al.. A study of pollution removal in exhaust gases from animal quartering centers by combining photocatalysis with surface discharge plasma: From pilot to industrial scale. Chemical Engineering and Processing: Process Intensification, 2017, 111, pp.1-6. 10.1016/j.cep.2016.10.001 . hal-01475458

HAL Id: hal-01475458

https://hal-univ-rennes1.archives-ouvertes.fr/hal-01475458

Submitted on 12 Jul 2017

HAL is a multi-disciplinary open access archive for the deposit and dissemination of scientific research documents, whether they are published or not. The documents may come from teaching and research institutions in France or abroad, or from public or private research centers.
L'archive ouverte pluridisciplinaire HAL, est destinée au dépôt et à la diffusion de documents scientifiques de niveau recherche, publiés ou non, émanant des établissements d'enseignement et de recherche français ou étrangers, des laboratoires publics ou privés. 
A study of pollution removal in exhaust gases from animal quartering

centers by combining photocatalysis with surface discharge plasma: from

pilot to industrial scale

ASSADI Aymen Amine ${ }^{a}$, BOUZAZA Abdelkrim ${ }^{a}$, SOUTREL Isabelle ${ }^{a}$, PETIT Philippe ${ }^{c}$,

MEDIMAGH Karim ${ }^{\mathrm{d}}$, WOLBERT Dominique ${ }^{\mathrm{a}}$

${ }^{\text {a }}$ Laboratoire Sciences Chimiques de Rennes - équipe Chimie et Ingénierie des Procédés, UMR 6226

CNRS, ENSCR-11, allée de Beaulieu, CS 508307-35708 Rennes, France.

${ }^{\mathrm{c}}$ Indoor Environment Laboratory, CIAT R\&D Centre, Av. Jean Falconnier, 01350 Culoz, France

${ }^{\mathrm{d}}$ EXPLORAIR, 340, Rue Laverlochère - Z.I. de l'Abbaye 38780 pont Evêque, France

E-mail address: Aymen.assadi@ensc-rennes.fr (A ASSADI) 


\section{Graphical absrtact}

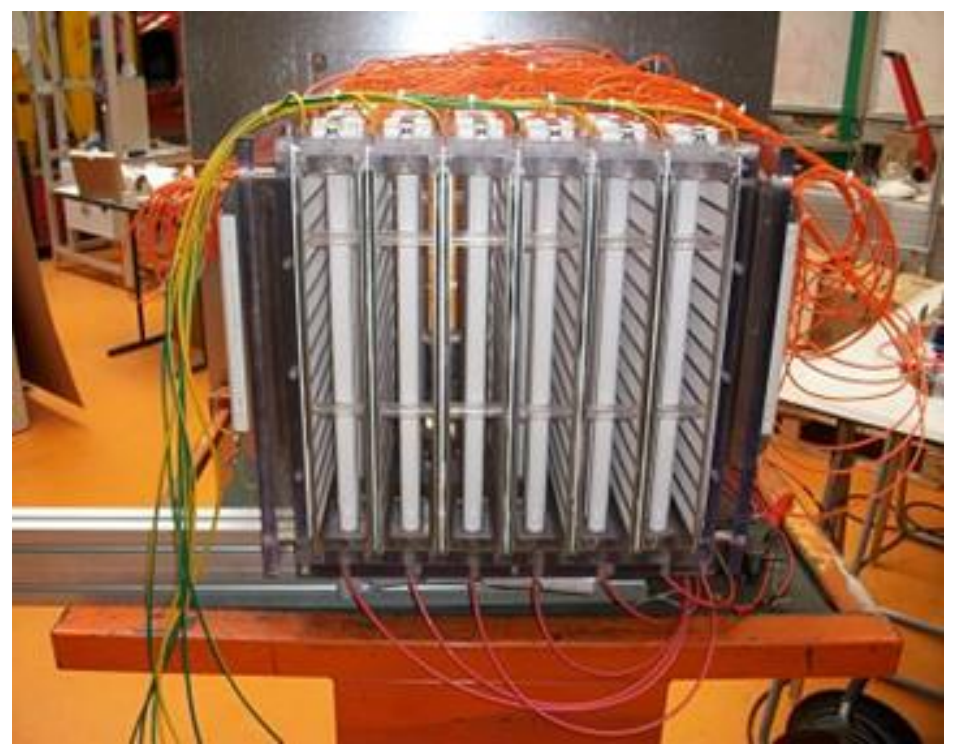

Photograph of prototype combining plasma and photocatalysis in situ

\section{Highlights:}

Isovaleraldehyde removal by plasma and photocatalysis is studied at pilot scale.

- A synergetic effect is confirmed at high value of flowrate.

- A real pollution from animal quartering centers has been treated.

- The associated system seems to be a potential method in removing air pollutants

\section{Abstract}

In this study, a continuous process combining plasma and photocatalysis, at pilot scale, has been investigated on pollution treatment.

The degradation efficiency and by-products formation has been monitored through the variation of multiple parameters such as inlet concentration, specific energy, and residence time. Results show that process combination leads to an enhancement of pollutant degradation compared to the separate systems even at high flow rate $\left(250 \mathrm{~m}^{3} \cdot \mathrm{h}^{-1}\right)$. Synergy factor due to this association ranged from 1.10 to 1.17 . Furthermore, $\mathrm{CO}_{2}$ selectivity has significantly 
improved when comparing the combined system to that with plasma alone. Moreover, we note that adding a photocatalyst in the discharge zone leads to a reduction of ozone and $\mathrm{CO}$ formation compared to plasma process alone.

Based on this investigation, a methodology of scaling up the combined system was proposed. Indeed, as a practical application, an industrial reactor has been developed and tested for treating a real pollution from animal quartering centers. This investigation indicates that the combined system of photocatalysis with plasma is a promising method for removing air pollutants.

Keywords: Photocatalysis, Plasma treatment, combined process, pilot scale, industrial application

\section{Introduction}

Many studies have shown that Volatile Organic Compounds (VOC) emissions are not negligible and their impacts on the environment and human health are serious and threatening [1-2]. Therefore, there is currently an important deal of interest in developing processes to treat air pollutants, such as photocatalytic $\left(\mathrm{UV} / \mathrm{TiO}_{2}\right)$ oxidation in the gas phase. $\mathrm{UV} / \mathrm{TiO}_{2}$ process is an attractive technique, as heterogeneous photocatalysis for environmental cleanup. It operates at ambient temperature and the by-products are usually $\mathrm{CO}_{2}, \mathrm{H}_{2} \mathrm{O}$ and nonharmful mineral acids [3-5]. Also, non-thermal plasma (NTP) is one of the most frequently used oxidation processes to control air pollution [6]. It consists of generating an electrical discharge that treats gas present between electrodes separated by a dielectric material. However, application of non-thermal plasma leads to low the mineralization [7]. Photocatalysis, due to its adsorption step, tends to keep the by-products in the adsorbed state 
in order to reach their complete oxidation, achieving, thus, a higher mineralization value [35]. Therefore, it is interesting to try enhancing NTP's activity by adding $\mathrm{TiO}_{2}$ with external UV [8]. Moreover, many researchers found that combining plasma and photocatalysis improved the global performance of the process [9-11]. Indeed, a synergetic effect can be expected between these technologies [9-11]. Although many studies were carried out on the efficiency of associated process at lab scale, the extrapolation of this process at industrial scale has not been extensively explored. Here, our methodology was to extend previous research $[12,13]$ by proposing a new investigation about plasma, photocatalysis and their association in-situ at pilot and industrial scales. Firstly, a special attention is given to the comparison of the obtained results at pilot scale with those obtained at lab-scale, which is innovative in comparison to latter studies [14]. The second innovation of this research is about the investigation of the real effluent treatment with an industrial reactor.

At pilot scale study, isovaleraldehyde was chosen as a test molecule because it is significantly present in exhaust gases from animal quartering [15]. Furthermore, it is listed as one of the surrogates for the six major classes of indoor VOCs (aromatic, aldehyde, alkane, ketone, alcohol, and chlorocarbon) by the French Environment and Energy Management Agency (ADEME) [15].

In this investigation, a new photocatalysis-surface plasma hybrid system is incorporated in a pilot reactor and the influence of some operating parameters on the removal of exhaust gases from animal quartering centers is investigated. On the other hand, at the same scale, Ochiai and co-workers investigated and developed a photocatalysis-plasma hybrid air-purification reactor using a titanium mesh sheet modified with $\mathrm{TiO}_{2}$ (TMiP TM) and a surface dischargeinduced plasma (SPCP) unit for treat a gas of smoking area [9].

Here, we test the combined system with a novel photocatalyst of glass fiber tissue combined with surface discharge plasma which is established in a continuous reactor to investigate the 
influence of some operating parameters on the removal in exhaust gases from animal quartering centers.

\section{Materials and methods}

\subsection{Materials and methods at pilot scale}

The experimental part will include two major elements: the reactor description and the gas sampling and analysis.

\subsubsection{Reactor description}

The experimental set-up is an air handling unit manufactured by CIAT (Compagnie Industrielle d'Applications Thermiques- France) with a flow rate capacity up to $5000 \mathrm{~m}^{3} \cdot \mathrm{h}^{-1}$ (Fig. 1). It contains a pre-filtration box, a cooling bank, a vapor humidifier and an electrical heater. The second box contains the pollutant injection zone. Two boxes (A \& B) permit an upstream and a downstream concentration pollution sampling. Photocatalytic and plasma treatment system is installed between these boxes (A \& B), and finally an activated carbon filter is maintained at the exit in order to adsorb the residual pollution. A booster is used to generate the air flow rate. Its quantification is done thanks to a diaphragm by measuring a pressure drop. A "Testo 625 " probe is used to measure the temperature and the relative humidity. This pilot was better described in our previous study concerning an investigation with photocatalysis alone [16].

Fig.1: A functional diagram of the used pilot unit 
The high voltage electrode was an array of grid wires placed at approximately $4 \mathrm{~mm}$ above the ground electrode. The grid had a thickness of $2 \mathrm{~mm}$ and the distance between adjacent wires was $20 \mathrm{~mm}$. The ground electrode was a copper tape placed into a plat of glass. The photocatalytic zone had a cross-section area $(0.30 \mathrm{~m} \times 0.30 \mathrm{~m})$. It contains the pleated photocatalytic media, which is maintained by grid wire into glass plate, offering a surface of $2.16 \mathrm{~m}^{2}$. This area was irradiated by 36 Philips UVA lamps (PL-L 24W/827/4P). The used material was a coated Glass Fiber Tissue (GFT) with $6.5 \mathrm{~g} \cdot \mathrm{m}^{-2}$ of colloidal silica to ensure the fixation of $6.5 \mathrm{~g} . \mathrm{m}^{-2}$ of titanium dioxide nanoparticles. It is supplied by Ahlstrom Research and Services. This photocatalytic material had been described in detail in our previous works

\section{$[3,12-14]$.}

Plasma was obtained by submitting the electrodes to a sinusoidal high voltage ranging from 0 to $30 \mathrm{kV}$ at a $50 \mathrm{~Hz}$ frequency. The outer electrode was connected to the ground through a 50 $\mathrm{nF}$ for collecting the charges transferred from the reactor. The applied voltage $\left(\mathrm{U}_{\mathrm{a}}\right)$ and high capacitance voltage $\left(\mathrm{U}_{\mathrm{m}}\right)$ were measured by LeCroy high voltage probes and recorded by a Lecroy oscilloscope (Wave Surfer 24 Xs, 200 MHz).

\subsubsection{Gas sampling and analysis}

The preparation of synthetic polluted air stream was largely described in previous studies [3, 12-14]. Briefly, the air-isovaleraldehyde gas mixture was prepared by passing synthetic air (Air Liquide) through liquid isovaleraldehyde (Sigma-Aldrich, 97\%). Indeed, pollutant liquid was heated, vaporized and mixed with a zero-air flow in an especially designed Bronkhorst vaporization/mixing chamber (CEM). In these conditions, the tested concentrations ranged from 2 to $10 \mathrm{mg} \cdot \mathrm{m}^{-3}$. Gas samples were analyzed by gas chromatography with flame 
ionization detection (Chrompact FFAP-CB column). A standard iodometric titration method was used to estimate the formation of the downstream ozone.

$\mathrm{CO}$ concentrations were measured by CO ZRE gas analyzer. To monitor the progression of pollutant mineralization, $\mathrm{CO}_{2}$ was analyzed by a Cosma Beryl analyzer reference 100 equipped by spectrophotometer Fourier Transform Infrared (FTIR) brand Environnement SA.

\subsection{Materials and methods at industrial application}

Several materials were used in order to better investigate and analyze the performance of combined system

\subsubsection{Analysis system}

The industrial emissions were measured by a FISONS Gas-phase Chromatograph (GC) using a Flame Ionisation Detector (FID). Indeed, different Carbotrap cartridges have been used in order to concentrate the pollution: Carbopack Y, allows the selective retention of heavy compounds from $\mathrm{C}_{12}$ to $\mathrm{C}_{20}$. Another Carbopack $\mathrm{B}$ traps the compounds $\mathrm{C}_{5}$ to $\mathrm{C}_{12}$, while the light compounds from $\mathrm{C}_{2}$ to $\mathrm{C}_{5}$ were adsorbed with Carboxen 1003. Thus, pollution was firstly concentrated on different Carbotrap (Supelco); the pumping was done by a Gillian LFS-113 pump under a flow rate of $50 \mathrm{~mL} \cdot \mathrm{min}^{-1}$. Secondly, Turbomatrix Perkin Elmer unit was used to desorb thermally the concentrated compounds, which will be analyzed through a transfer line to the GC/MS Perkin Elmer Clarus 500. A detailed description of the experimental protocol of analysis was published elsewhere [13]. In addition, TRS MEDOR analyzer (Chromatotec, France) was used to analyze the sulfur compounds concentrations. In fact, the 


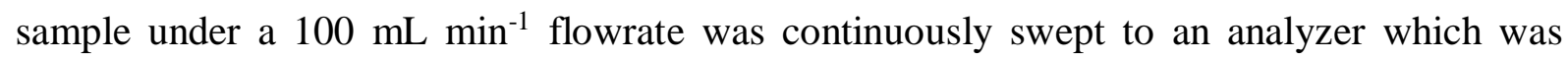
equipped by a capillary column and an electrochemical detection [14].

Along with the concentration on Carbotrap, a series of analysis were done in-situ using the equipment provided by Explorair Company (France). A thermal desorption unit coupled to Fast Gas Chromatograph-Mass spectrometer (TD/FASTGC/MS) was used to analyze concentration at different sampling points A, B, C and D (Fig.2). This TD/FAST GC/MS gives new possibilities for continuous analysis by offering excellent performances represented by the speed, flexibility, sensitivity and repeatability of the analysis. An RTX column (20 m length $0.18 \mathrm{~mm}$ external diameter and $1 \mu \mathrm{m}$ thickness), which is especially adapted for volatile fatty acids, was used. Helium gas constituted the mobile phase. A Micro Gas Chromatograph-Mass spectrometer ( $\mu \mathrm{GC} / \mathrm{MS})$ was used to analyze mercaptans.

\section{Fig.2: photography of industrial pilot at Saria with different sampling}

In order to analyze ammonia after pumping and bubbling it through an $\mathrm{HCl}$ solution of $40{\mathrm{~L} . \mathrm{h}^{-}}^{-}$

${ }^{1}$ of downstream, a spectrophotometric method using Nessler reagent was used [14].CO, $\mathrm{CO}$, and NOx were analyzed with the same equipment that was used at pilot scale investigation. Ozone was monitored on-line by an ozone analyzer (Environnement SA_O342M).

\subsubsection{Industrial reactor description}

A second prototype ( $\operatorname{Pr} 2)$ was built for the industrial application. This prototype had the same configuration that Pr1 with only some technical improvements over the distance between UV light and electrodes. $\operatorname{Pr} 1$ and $\operatorname{Pr} 2$ were inserted and connected in series in the industrial reactor which had the same configuration as the pilot reactor. Indeed, it was designed with a $316 \mathrm{~L}$ 
stainless steel to be able to withstand corrosion induced by the chemical compounds. It comprised a pre-filtration box, an upstream pollution measurement box, two boxes for prototypes $(\operatorname{Pr} 1 \& 2)$, and a downstream concentration measurement box. A ventilation box consisted of a medium-pressure centrifugal fan is added. This scroll-free fan was coupled directly to a $3 \mathrm{~kW}$ motor. The assembly was capable of generating an air flow rate ranging from 0 to $1000 \mathrm{~m}^{3} \cdot \mathrm{h}^{-1}$.

In order to generate the plasma in both prototypes, the same system as for pilot scale investigation was used. The second plasma generating system came from the Institut de Chimie des Milieux et Materiaux de Poitiers (IC2MP). This second high voltage power amplifier (Trek 30/20A) driven by a function generator (FLUKE_271 DDS) was used to generate a sine waveform [10]. The high voltage applied $\left(U_{a}\right)$ and the voltage across the capacity $\left(\mathrm{U}_{\mathrm{m}}\right)$ were measured by LeCroy high voltage probes and the signals were visualized with a digital oscilloscope (Lecroy_model LT342, $500 \mathrm{MHz}$ ) [10]. Results at lab and pilot scales showed that the used material (Glass Fiber Tissue (GFT) can resist to the discharge. Thus, this photocatalytic medium was maintained for industrial test.

\section{Results and discussion}

\subsection{Investigation at pilot scale}

In order to monitor the performance of the process, some operational conditions were studied. Process efficiency was evaluated thanks to the following parameters:

- Specific energy $\left(\mathrm{SE} ; \mathrm{J} . \mathrm{L}^{-1}\right)=3600 *\left(\mathrm{P}(\mathrm{W}) / \mathrm{Q}\left(\mathrm{m}^{3} \cdot \mathrm{h}^{-1}\right)\right) / 1000$

where $\mathrm{P}$ is input power adjusted by changing the applied voltage $\left(\mathrm{U}_{\mathrm{a}}\right)$ and $\mathrm{Q}$ is the flowrate

- $\mathrm{CO}_{2}$ and $\mathrm{CO}$ selectivity's are calculated according to the following equations: 


$$
\begin{aligned}
& S_{\mathrm{CO}_{2}}=\frac{\Delta \mathrm{CO}_{2}}{\mathrm{n}_{(\mathrm{C} \mid \mathrm{COV})^{\cdot} \cdot\left([\mathrm{COV}]_{0}-[\mathrm{COV}]_{\mathrm{s}}\right)}}
\end{aligned}
$$

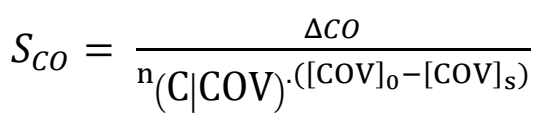

where $[\mathrm{COV}]_{0}$ and $[\mathrm{COV}]_{\mathrm{s}}$ are the inlet and outlet concentrations of Isoval respectively (ppmv), $\mathrm{n}_{(\mathrm{C} \mid \mathrm{COV})}$ is the stoichiometric coefficient of the removal reaction. In our case it is equal to 5 .

Ozone production is investigated by several researchers and correlated with numerical simulation [17]. Indeed, non-thermal plasma leads to ozone formation through the production of oxygen atoms by electron collisions on $\mathrm{O}_{2}$ :

$$
\mathrm{O}_{2}+\mathrm{e}^{-} \rightarrow 2 \mathrm{O}^{\cdot}+\mathrm{e}^{-}
$$

followed by an addition reaction:

$$
\mathrm{O}^{\bullet}+\mathrm{O}_{2}+\mathrm{M} \rightarrow \mathrm{O}_{3}+\mathrm{M}, \text { with } \mathrm{M}=\mathrm{N}_{2} \text { or } \mathrm{O}_{2}
$$

where $\mathrm{O}^{\bullet}$ refers to atomic oxygen which was generated by $\mathrm{O}_{2}$ dissociation due to impact with plasma discharge.

\subsubsection{Removal efficiency}

Fig.3 shows the variation of Isoval oxidation efficiency with plasma, photocatalysis, and associated process. It has been proved that the UV light generated by the DBD plasma reactor did not activate the photocatalytic medium [13]. Thus, introducing the photocatalyst with external UV into the plasma zone causes an enhancement in the oxidation efficiency due to the generation of more reactive species $[19,20]$. At lab-scale, previous studies had shown that coupling plasma with photocatalysis induced a synergetic effect of the oxidation efficiency on the entire process $[\mathbf{8}, \mathbf{1 8}, \mathbf{2 0}]$. In our case, the novelty is that this synergetic effect was 
maintained at high flow rates (25 times higher than that at the lab- scale). Indeed, Isoval oxidation efficiency with the associated system was $8 \%$ higher than the sum of the oxidation efficiencies recorded, under the same conditions when plasma and photocatalysis were used separately. This result is similar to that obtained by Ochiai and co-workers. In fact, they investigated and developed a photocatalysis-plasma hybrid air-purification reactor using a titanium mesh sheet modified with $\mathrm{TiO}_{2}$ (TMiP TM) and a surface discharge-induced plasma (SPCP) unit [5, 9].

\section{Fig. 3: Oxidation efficiency of three tested processes at pilot scale $\left(E_{i n j}=6 \mathrm{~J}^{-L^{-1}}\right.$, [Isoval] $=14 \mathrm{mg} \cdot \mathrm{m}^{-3}$ et $\left.\mathrm{Q}=250 \mathrm{~m}^{3} \cdot \mathrm{h}^{-1}\right)$.}

The synergetic effect can be ascribed to:

- Different chemical mechanisms which can occur when non-thermal plasma is present due to free radicals $\left(\mathrm{N}^{*}, \mathrm{O}^{*}, \mathrm{H}^{*}, \mathrm{OH}^{*}\right)$ created through dissociation of the background gas molecules $\left(\mathrm{N}_{2}, \mathrm{O}_{2}, \mathrm{H}_{2} \mathrm{O}\right)$. These actives species can interact directly with Isoval molecules [19].

- Desorption of $\mathrm{TiO}_{2}$ surface in the presence of plasma [19] due to ionic winds.

- Decomposition of ozone on the surface of $\mathrm{TiO}_{2}$ which gives more actives species such as $\mathrm{O}^{\bullet}[10,12]$.

\subsubsection{By-products formation}

Table 1 gives the list of the by-products detected. At pilot scale, we note an improvement of mineralization when plasma was associated with photocatalysis. In fact, the mineralization by photocatalytic process is about $75 \%$ and it is equal to $27 \%$ when plasma was taken alone. Nevertheless, with the associated process, $\mathrm{CO}_{2}$ selectivity exceeds $55 \%$. This enhancement is 
attributed to the formation of more reactive species due to the presence of $\mathrm{TiO}_{2}$ in plasma zone $[9,13]$. On the other hand, CO selectivity doesn't exceed $10 \%$ with combined process. It is interesting to note that the combined system leads to better $\mathrm{CO}_{2}$ selectivity than for plasma. Thus CO can be decomposed with plasma because recent reports by Ochiai et al. indicate that although using combined system, CO cannot decompose successfully [21, 22]. Moroever, many research works confirm that such mineralization improvements are related to the porosity of the medium: porosity induces a longer residence time of gas intermediates byproducts during diffusion through the solid pore system [14]. This behavior can enhance the converting of intermediates by-products into $\mathrm{CO}_{2}$ leading to the little amount of $\mathrm{CO}$.

These behaviors of selectivity are similar to that was observed at lab-scale experiments. In fact, this trend is attributed to the role of $\mathrm{TiO}_{2}$ in the discharge zone which leads to the formation of more reactive species. Moreover, external UV light is able to activate ozone on the surface of $\mathrm{TiO}_{2}$ in order to improve the byproducts mineralization. Consequently, intermediates by-products have been reduced due to various other species $\left(\mathrm{O}^{\bullet}, \mathrm{N}, \mathrm{OH}^{\bullet}, \mathrm{O}_{2}{ }^{-}\right.$, $\mathrm{O}_{3}, \mathrm{NO}_{2}, \mathrm{NOx}$, etc.) [5].

In the same way, the combined process performance was enhanced in term of residual ozone. Indeed, the results show that residual ozone formed by plasma alone is higher than that formed with the associate system. This can be explained by the decomposition of ozone due to the presence of external UV $[\mathbf{8 , 1 0}$. Similar laboratory trends were also observed at pilot scale under various operating parameters [13].

Table 1: $\mathrm{CO}$ and $\mathrm{CO}_{2}$ selectivities and residual ozone with different processes at pilot scale experiments

\subsection{Industrial application}


SARIA Industries is an animal quartering centers. It collects from farmers and meat industry the waste which can represent a risk to human health and environment. This waste is then subject to specific treatments within dedicated industrial units. These treatments generate a polluted gas effluent loaded with VOCs and ammonia.

Our treatment plant was installed on SARIA factory on mid-June 2012. The tests began during the second half of June under high temperature $\left(32.4{ }^{\circ} \mathrm{C}\right)$ and relative humidity $(56 \%)$. Before turning on the fan, a filter for dust and grease retention was positioned upstream of the pilot plant. The inlet concentration of pollutants (primarily aldehydes) was not stable and depends on the plant quartering centers. This forces us to alternate systematically analysis upstream and downstream of the industrial pilot.

\subsubsection{Photocatalysis alone}

The results of VOC's oxidation are represented in fig. 4. After a stabilization period of several hours, the oxidation efficiency with photocatalysis alone was hovering around $21-24 \%$ for the three aldehydes (isobutyraldehyde, isovaleraldehyde, and 2-methylbutyraldehyde). Additionally, oxidation efficiency of ammonia was around $25 \%$ with inlet concentration about $20 \mathrm{mg} \cdot \mathrm{m}^{-3}$. On the other hand, we also note the formation of byproducts, mainly acetic acid, propionic acid and butanoic acid.

Fig. 4: The removal efficiencies of some pollutants of SARIA effluent using photocatalysis alone (Total pollution $\left.=\sim 30 \mathrm{mg} \cdot \mathrm{m}^{-3}, \mathrm{Q}=350 \mathrm{~m}^{3} \cdot \mathrm{h}^{-1}\right)$. 
However, the values of removal efficiencies in the industrial application were less than the pilot study. In fact, the high relative humidity observed for the real effluent has a significant effect. This behavior arises because water vapor can deposit on the surface of the photocatalyst and occupy its active sites [13]. If the number of active sites is considered constant, it becomes evident that the competitive effect increases with increasing effluent humidity.

\subsubsection{DBD plasma alone}

The oxidation efficiencies of some aldehydes and mercaptans with plasma surface discharge alone are summarized in Fig.5. Except isovaleraldehyde, the oxidation efficiencies were around 30-35\%. The removal efficiency of dimethyl disulfide (DMDS) with low inlet concentration $\left(<10 \mathrm{mg} / \mathrm{m}^{3}\right)$ doesn't exceed $40 \%$.This low degradation rate is usually observed for sulfur compounds [14].

In fact, with hydrogen sulfide, at similar value of plasma injected energy, the conversion efficiency does not exceed $25 \%$ [14].

Additionally, the same behavior has been observed with the aldehydes. The increase of water vapor content reduces the electron density and quenches the active chemical species $[4,5]$.

Fig.5: Removal efficiencies of pollutants present in SARIA effluent using surface discharge alone $\left(\right.$ Total pollution $\left.=\sim 30 \mathrm{mg} \cdot \mathrm{m}^{-3}, \mathrm{~T}=30^{\circ} \mathrm{C}, \mathrm{RH}=53 \%, \mathrm{Q}=350 \mathrm{~m}^{3} \cdot \mathrm{h}^{-1}\right)$.

\subsubsection{Combined DBD plasma/photocatalysis}


As shown in Fig.6, it is clear that the combination of plasma and photocatalysis improve the performance of the industrial reactor. In fact, the oxidation efficiencies were around $60-75 \%$ for the three aldehydes.

Here, the synergetic effect was not clear because operating parameters like the temperature, the inlet concentration of pollutant and relative humidity were not stable during all the experiments. This may be the most serious problem for providing and confirming a synergetic effect at industrial scale.

Moreover, the high value of $\mathrm{RH}$ can affect also the synergistic effect in combined DBD plasma/photocatalysis. Indeed, the removal efficiency due to the combined process is not alltime better than the value corresponding to the sum of the removal efficiencies of each process taken separately.

On one hand, with combined DBD plasma/photocatalysis, water vapor content may enhances the formation of reactive species as in the equation [13]:

$$
\mathrm{H}_{2} \mathrm{O}+\mathrm{e}^{-} \rightarrow \mathrm{H}^{\bullet}+\mathrm{HO}^{\bullet}
$$

On the other hand, at higher levels of RH, water vapor content limits the electron density and quenches the active chemical species $[4,5]$.

Thus, the reactor at the pilot scale in this study is more efficient than the industrial system.

Fig. 6: The removal efficiencies of some pollutants present in the effluent of SARIA using combined system $\left(\right.$ Total pollution $\left.=30 \mathrm{mg} \cdot \mathrm{m}^{-3}, \mathrm{~T}=30^{\circ} \mathrm{C}, \mathrm{RH}=53 \%, \mathrm{Q}=350 \mathrm{~m}^{3} \cdot \mathrm{h}^{-1}\right)$.

Fig. 7 shows inorganic by-products concentrations. As we can see, with combined system, $\mathrm{CO}_{\mathrm{x}}, \mathrm{NO}_{\mathrm{x}}$ and ozone were detected. Since the combined process produces higher quantities of electrons and reactive species ( $\operatorname{such}$ as $\mathrm{O}^{\circ}$ and $\mathrm{HO}^{\circ}$ ), this latter oxidize then the pollutants' 
molecules into $\mathrm{CO}_{2}$ and $\mathrm{CO}[24]$. These results were in agreement with lab works treating the removal of some VOCs $[\mathbf{1 0}, \mathbf{1 2}]$. Ozone was detected downstream the reactor at a lower concentration than that obtained at lab-scale study. This is probably due to the elevated temperature and the higher relative humidity in the air. In fact, an elevated temperature leads to a higher decomposition of ozone and an oxidation of $\mathrm{NO}$ molecules to $\mathrm{NO}_{2}$ [23].

Moreover, the previous result at lab-scale showed that ozone is strongly reduced when $\mathrm{RH}$ increases. Its formation is probably inhibited $[\mathbf{2 5}, \mathbf{2 6}]$. Indeed, the consumption of ozone in the presence of radicals $\left(\mathrm{H}^{\bullet}+\mathrm{HO}^{\circ}\right)$ due to electronic impact on water can be explained by these two reactions:

$$
\begin{gathered}
\mathrm{O}_{3}+\mathrm{OH}^{\bullet} \rightarrow \mathrm{O}_{2}+\mathrm{HO}_{2} \\
\mathrm{O}_{3}+\mathrm{H}^{\cdot} \rightarrow \mathrm{O}_{2}+\mathrm{HO}^{\bullet}
\end{gathered}
$$

Fig. 7: Temporal monitoring of inorganic by-products concentrations at downstream of industrial reactor $\left(\right.$ Total pollution $\left.=30 \mathrm{mg} \cdot \mathrm{m}^{-3}, \mathrm{~T}=30^{\circ} \mathrm{C}, \mathrm{RH}=53 \%, \mathrm{Q}=350 \mathrm{~m}^{3} \cdot \mathrm{h}^{-1}\right)$.

\section{Conclusion}

The main results of combined plasma photocatalytic treatment were:

(1) The effect of associated treatment is higher than the sum of individual steps. This synergy is partly confirmed at pilot scale with high values of flowrate.

(2) Plasma-assisted photocatalytic process can provide a suitable alternative for the pollution classic treatments.

(3) At pilot scale, the associated process leads towards total oxidation. The by-products formed during plasma treatment are oxidized to $\mathrm{CO}_{2}$. 
Globally, the transition to an industrial experiment was studied and discussed using industrial prototypes. It brought many interesting facts about the viability of the process in complex environments. The scale-up feasibility of the process seems to be possible for the treatment of an industrial and real gas effluent.

\section{Acknowledgment}

We gratefully acknowledge the financial support provided by the French National Research Agency (ANR) for this research work. We would like also to thank SARIA group for assistance provided within the scope of this industrial application and VALLET C., TATIBOUET J. M. and BATIOT-DUPEYRAT C. for their assistances

\section{References}

[1] P. Le Cloirec (2002) Introduction au traitement de l'air, Les techniques de l'ingénieur Traité environnement (G 1700) 1-8.

[2] International Programme on Chemical Safety (IPCS), OECD screening information databases 3-methyl butanal. UNEP, Canadian Centre for Occupational Health and Safety (CCOHS), 2004.

[3] A.A. Assadi, A. Bouzaza, D. Wolbert, Photocatalytic oxidation of Trimethylamine and Isovaleraldehyde in an annular reactor: Influence of the Mass Transfer and the relative humidity. Journal of Photochemistry and Photobiology A: Chemistry 236 (2012) 61-69. 
[4] P. Pichat, Some views about indoor air photocatalytic treatment using $\mathrm{TiO}_{2}$ : Conceptualization of humidity effects, active oxygen species, problem of $\mathrm{C}_{1}-\mathrm{C}_{3}$ carbonyl pollutants, Applied Catalysis B: Environmental 99 (2010) 428-434.

[5] T. Ochiai, A. Fujishima, Photoelectrochemical properties of $\mathrm{TiO}_{2}$ photocatalyst and its applications for environmental purification, J. Photochem. Photobiol. C: Photochem. Rev. 13 (2012) 247-262.

[6] T. Ochiai, Environmental and Medical Applications of $\mathrm{TiO}_{2}$ Photocatalysts and Borondoped Diamond Electrodes, Electrochemistry, 82 (2014) 720-725.

[7] A.A. Assadi, A. Bouzaza, M. Lemasle, D.Wolbert, Removal of trimethylamine and isovaleric acid from gas streams in a continuous flow surface discharge plasma reactor, Chemical engineering research and design 93 (2015), 640-651.

[8] J. Taranto, D. Frochot, P. Pichat, Combining Cold Plasma and $\mathrm{TiO}_{2}$ Photocatalysis To Purify Gaseous Effluents: A Preliminary Study Using Methanol-Contaminated Air, Ind. Eng. Chem. Res. 46 (2007) 7611-7614.

[9] T. Ochiai, Y. Hayashi, M. Ito, K. Nakata, T. Murakami, Y. Morito, A. Fujishima, An effective method for a separation of smoking area by using novel photocatalysis-plasma synergistic air-cleaner, Chem. Eng. J. 209 (2012) 313-317. 
[10] A. Maciuca, C. Batiot-Dupeyrat, J-M. Tatibouët, Synergetic effect by coupling photocatalysis with plasma for low VOCs concentration removal from air, Applied Catalysis B: Environmental, 125 (2012) 432-438

[11] C. Kletta, X. Dutena, S. Tiengb, S. Toucharda, P. Jestina, K. Hassounia, A. VegaGonzáleza, Acetaldehyde removal using an atmospheric non-thermal plasmacombined with a packed bed: Role of the adsorption process, Journal of Hazardous Materials 279 (2014) 356364

[12] A. A. Assadi, J. Palau, A. Bouzaza, J. Penya-Roja, V. Martinez-Soria, D. Wolbert, Abatement of 3-methylbutanal and trimethylamine with combined plasma and photocatalysis in a continuous planar reactor, Journal of Photochemistry and Photobiology A: Chemistry 282 (2014) 1-8.

[13] A.A. Assadi, A. Bouzaza, D. Wolbert, Use of DBD plasma, photocatalysis, and combined DBD plasma/photocatalysis in a continuous annular reactor for isovaleraldehyde elimination - synergetic effect and byproducts identification. Chemical Engineering Journal 254 (2014) 124-132.

[14] M. Guillerm, A.A Assadi, A. Bouzaza, D. Wolbert, Removal of gas-phase ammonia and hydrogen sulfide using photocatalysis, nonthermal plasma, and combined plasma and photocatalysis at pilot scale, Environmental Science and Pollution Research, 22 (2014)1312713137.

[15] ADEME, Pollutions olfactives : origine, législation, analyse, traitement. Ademe, Dunod, Angers, 2005 
[16] A. A. Assadi, A. Bouzaza, D. Wolbert, P. Petit, Isovaleraldehyde elimination by $\mathrm{UV} / \mathrm{TiO}_{2}$ photocatalysis: comparative study of the process at different reactors configurations and scales, Environmental Science and Pollution Research, 21 (2014) 11178-11188.

[17] M. Capitelli, Plasma kinetics in atmospheric gases, C.-M. Ferreira, B. Gordiets, A. Osipov (Eds.), in: Springer Series on Atomic, Optical, and Plasma Physics, vol. 31, SpringerVerlag, Berlin, 2000.

[18] A. A. Assadi, A. Bouzaza, S. Merabet, D. Wolbert, Modeling and simulation of VOCs removal by nonthermal plasma discharge with photocatalysis in a continuous reactor: Synergetic effect and mass transfer, Chemical Engineering Journal 258 (2014) 119-127

[19] Sh. Tang, N. Lu, J. Li, K. Shang, Y. Wu, Improved phenol decomposition and simultaneous regeneration of granular activated carbon by the addition of a titanium dioxide catalyst under a dielectric barrier discharge plasma, Carbon 53 (2013) 380-390

[20] O. Guaitella, F. Thevenet, E. Puzenat, C. Guillard, A. Rousseau, $\mathrm{C}_{2} \mathrm{H}_{2}$ oxidation by plasma $/ \mathrm{TiO}_{2}$ combination: Influence of the porosity, and photocatalytic mechanisms under plasma exposure, Applied Catalysis B: Environmental. 80 (2008) 296-305.

[21] T. Ochiai, E. Ichihashi, N. Nishida, T. Machida, Y. Uchida, Y. Hayashi, Y. Morito , A. Fujishima, Field performance test of an Air-Cleaner with photocatalysis-plasma synergistic reactors for practical and long-term use, Molecules, 19 (2014) 17424-17434. 
[22] T. Ochiai, Y. Hayashi, E. Ichihashi., T. Machida, Y. Uchida, Sh.Tago1, Y. Morito, A. Fujishima, Development of a Coil-Shape Photocatalysis-Plasma Synergistic Reactor for a Practical and Long-Term Usable Air-Cleaner, American Journal of Analytical Chemistry (2014) 5, 467-472.

[23] N. Dubus, Contribution à l'étude thermique d'un réacteur à décharge à barrière diélectrique, Thèse-Ecole Supérieure d'Ingénieurs de Poitiers (2009).

[24] Van Durme, J., Dewulf, J., Leys, C., Van Langenhove, H. Combining non-thermal plasma with heterogeneous catalysis in waste gas treatment: A review. Applied Catalysis B: Environmental 78, (2008) 324-333.

[25] F. Thevenet, O. Guaitella, E. Puzenat, C. Guillard, A. Rousseau, 2008. Influence of water vapour on plasma/photocatalytic oxidation efficiency of acetylene, Applied Catalysis B: Environmental, 84 (2008) 813-820.

[26] J. Chen, Effect of relative humidity on electron distribution and ozone production by DC coronas in air, IEEE transactions on plasma science, 33 (2005) 808-812. 
Figures

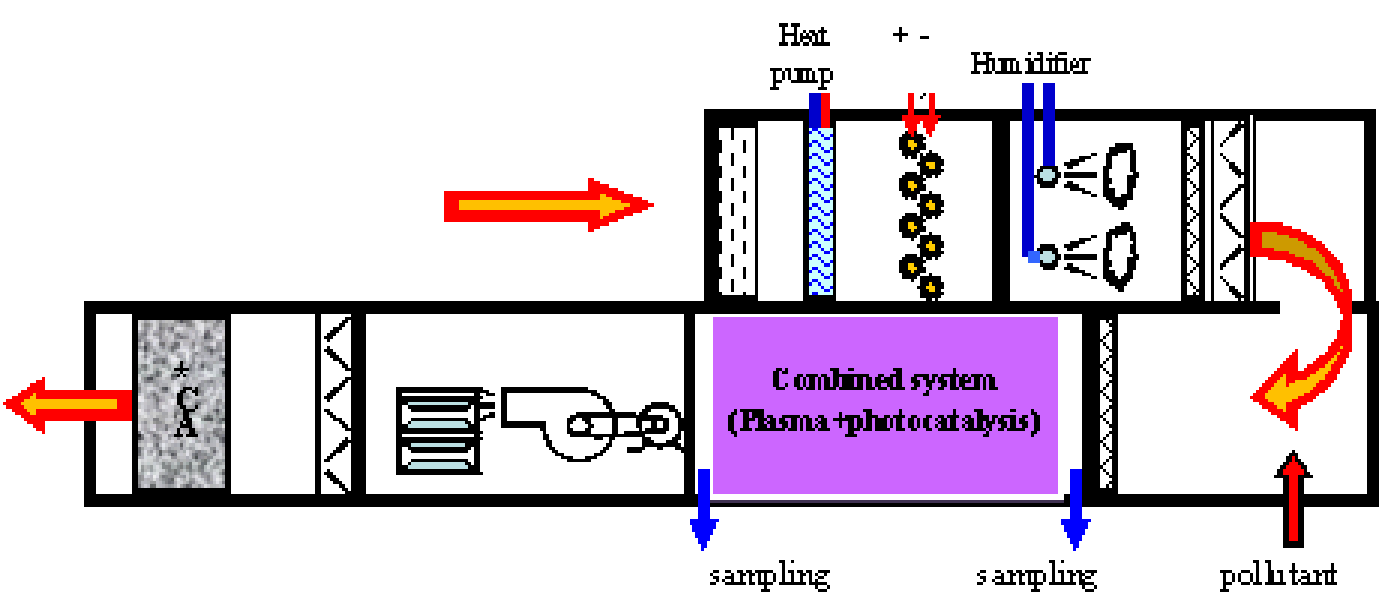

Fig.1: A functional diagram of pilot unit supplied by CIAT 


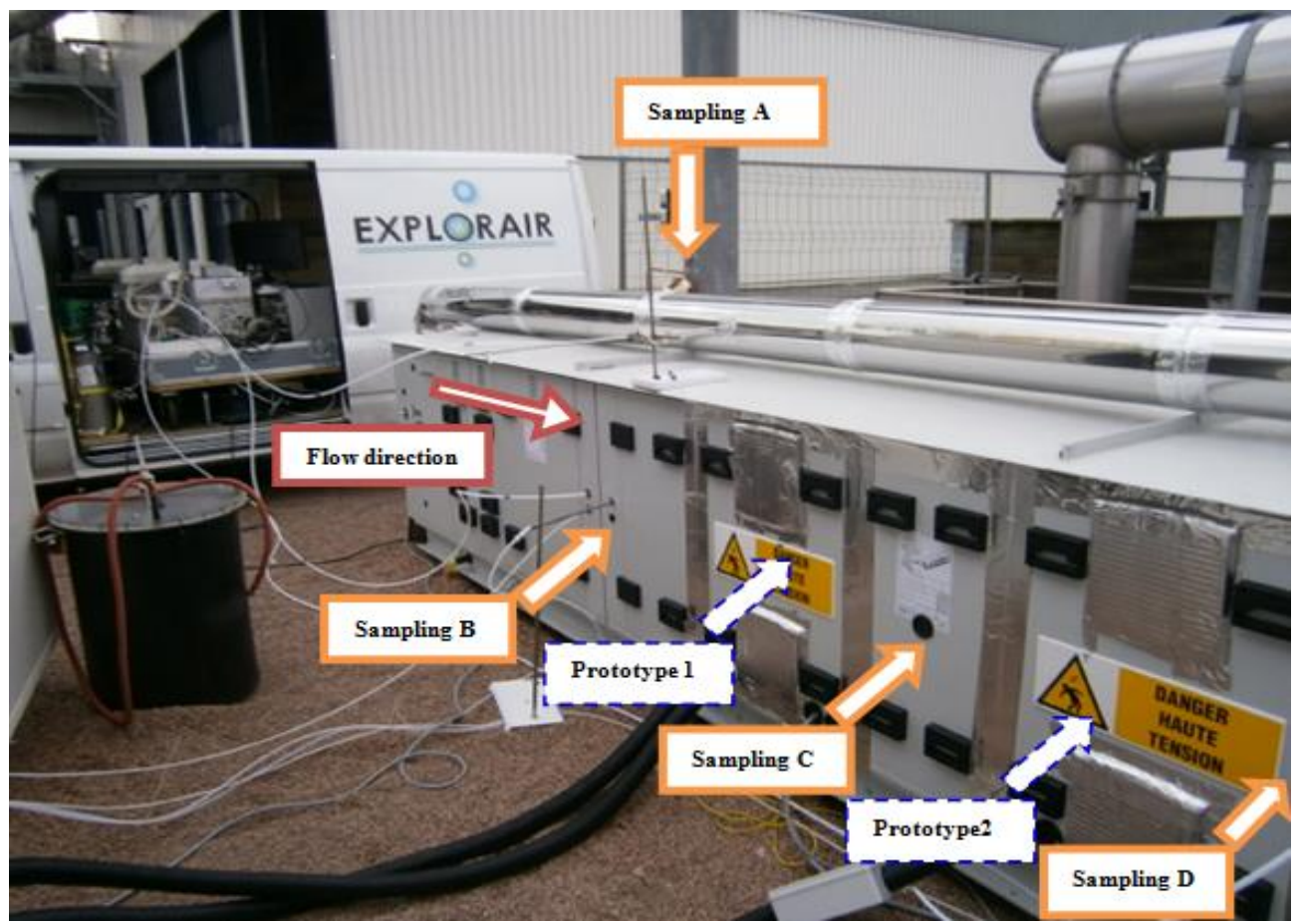

Fig.2: photography of industrial pilot at Saria with different sampling 


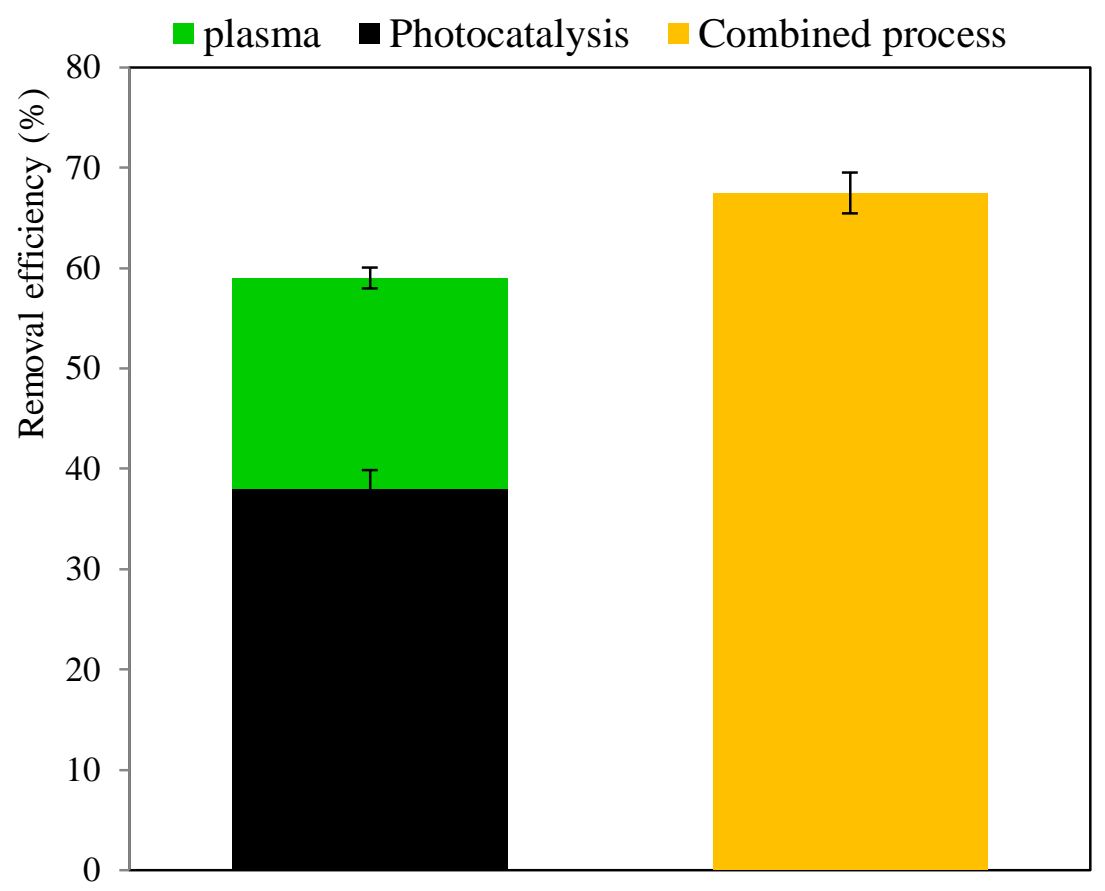

Fig. 3: Oxidation efficiency of three tested processes at pilot scale $\left(E_{\text {inj }}=6 \mathrm{~J} . \mathrm{L}^{-1}\right.$, [Isoval $]=14 \mathrm{mg} \cdot \mathrm{m}^{-3}$ et $\left.\mathrm{Q}=\mathrm{m}^{3} \cdot \mathrm{h}^{-1}\right)$. 


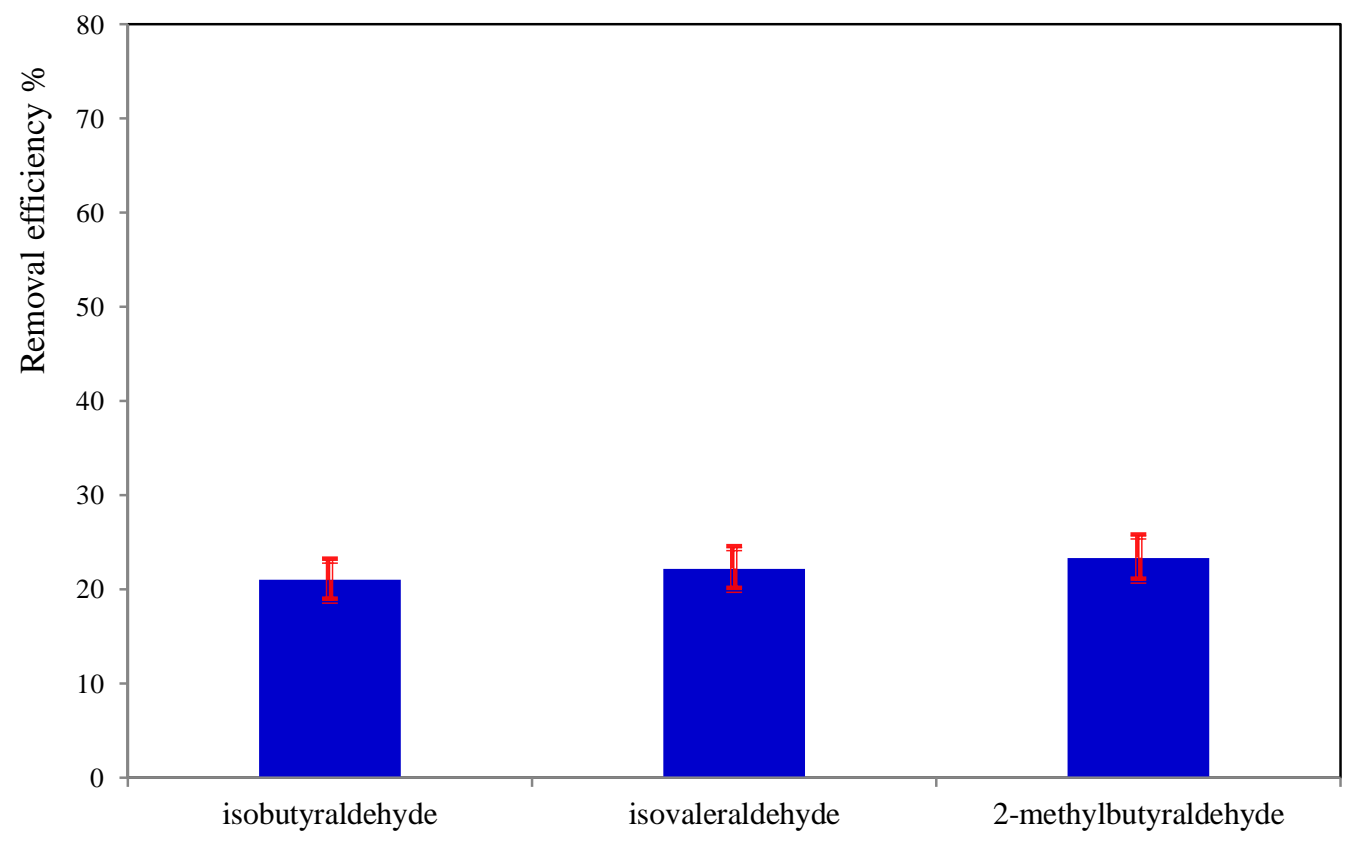

Fig. 4: The removal efficiencies of some pollutants of SARIA effluent using photocatalysis alone (Total pollution $\left.=\sim 30 \mathrm{mg} \cdot \mathrm{m}^{-3}, \mathrm{Q}=350 \mathrm{~m}^{3} \cdot \mathrm{h}^{-1}\right)$. 


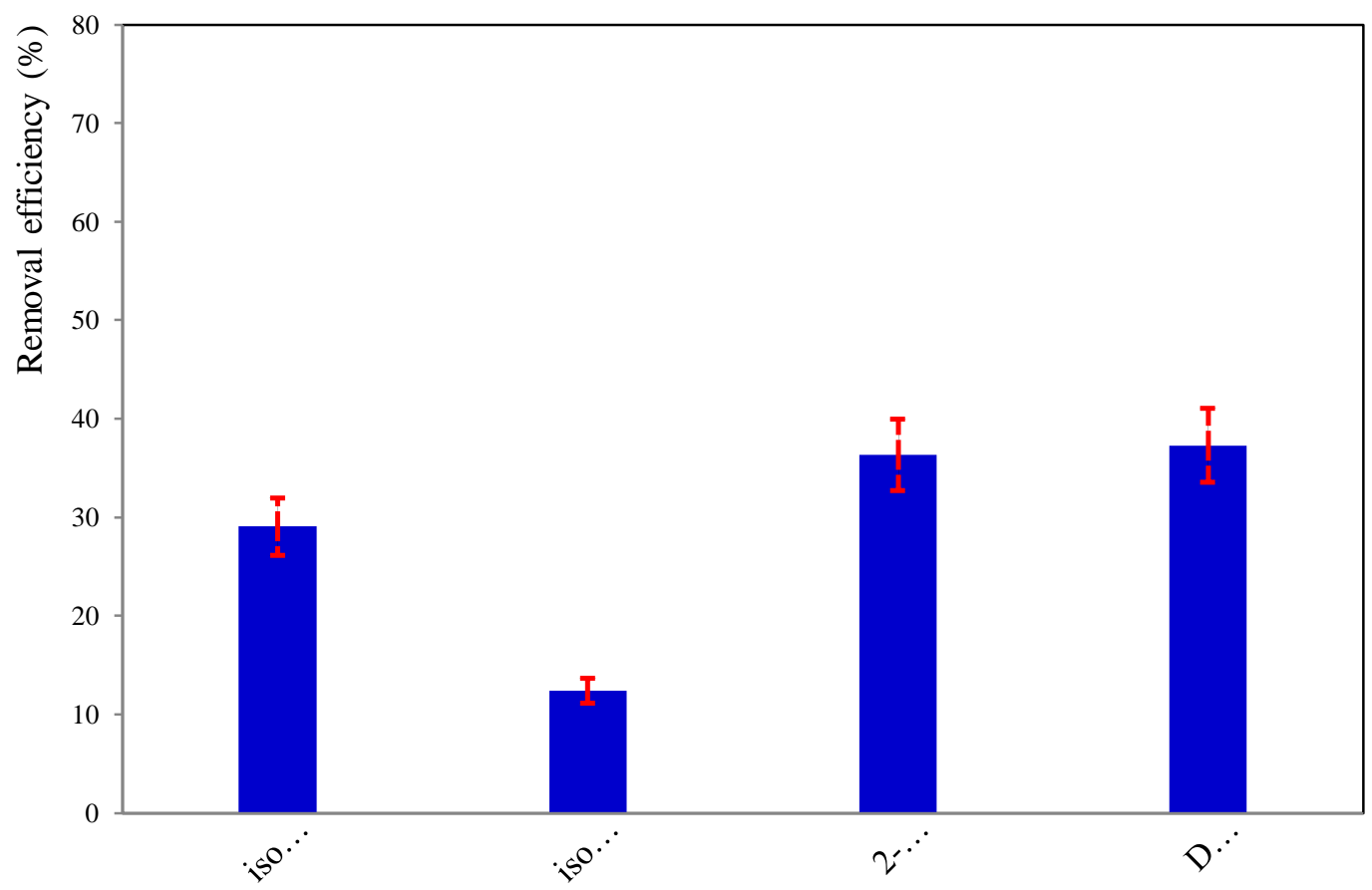

Fig. 5: Removal efficiencies of pollutants present in SARIA effluent using surface discharge alone (Total pollution $=\sim 30 \mathrm{mg}^{-3} \mathrm{~m}^{-3}, \mathrm{~T}=30^{\circ} \mathrm{C}, \mathrm{RH}=53 \%, \mathrm{Q}=350 \mathrm{~m}^{3} \cdot \mathrm{h}^{-1}$ ) 


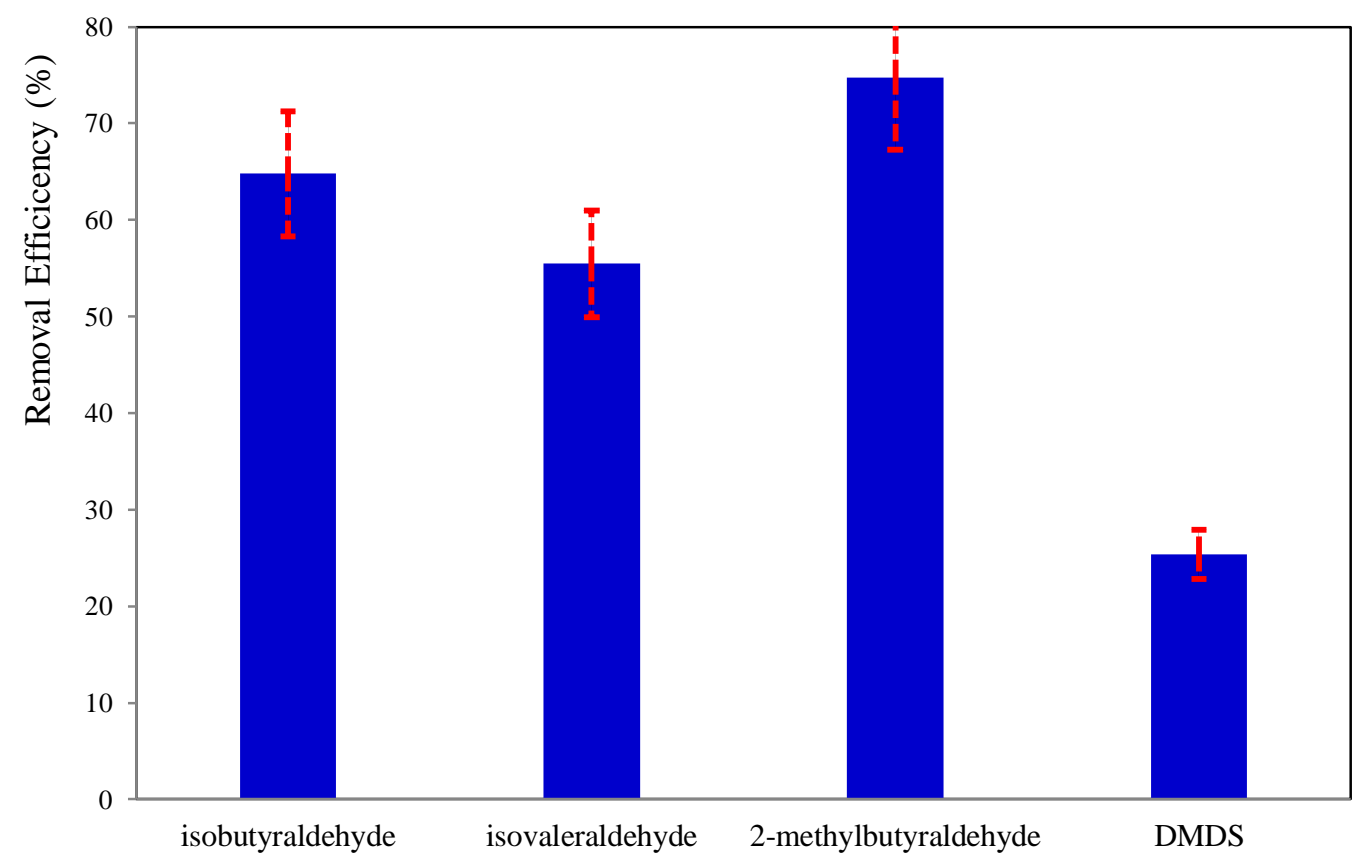

Fig. 6: The removal efficiencies of some pollutants present in the effluent of SARIA using combined system (Total pollution $=\sim 30 \mathrm{mg}^{-3} \mathrm{~m}^{-3}, \mathrm{~T}=30^{\circ} \mathrm{C}, \mathrm{RH}=53 \%, \mathrm{Q}=350 \mathrm{~m}^{3} \cdot \mathrm{h}^{-}$ 1). 


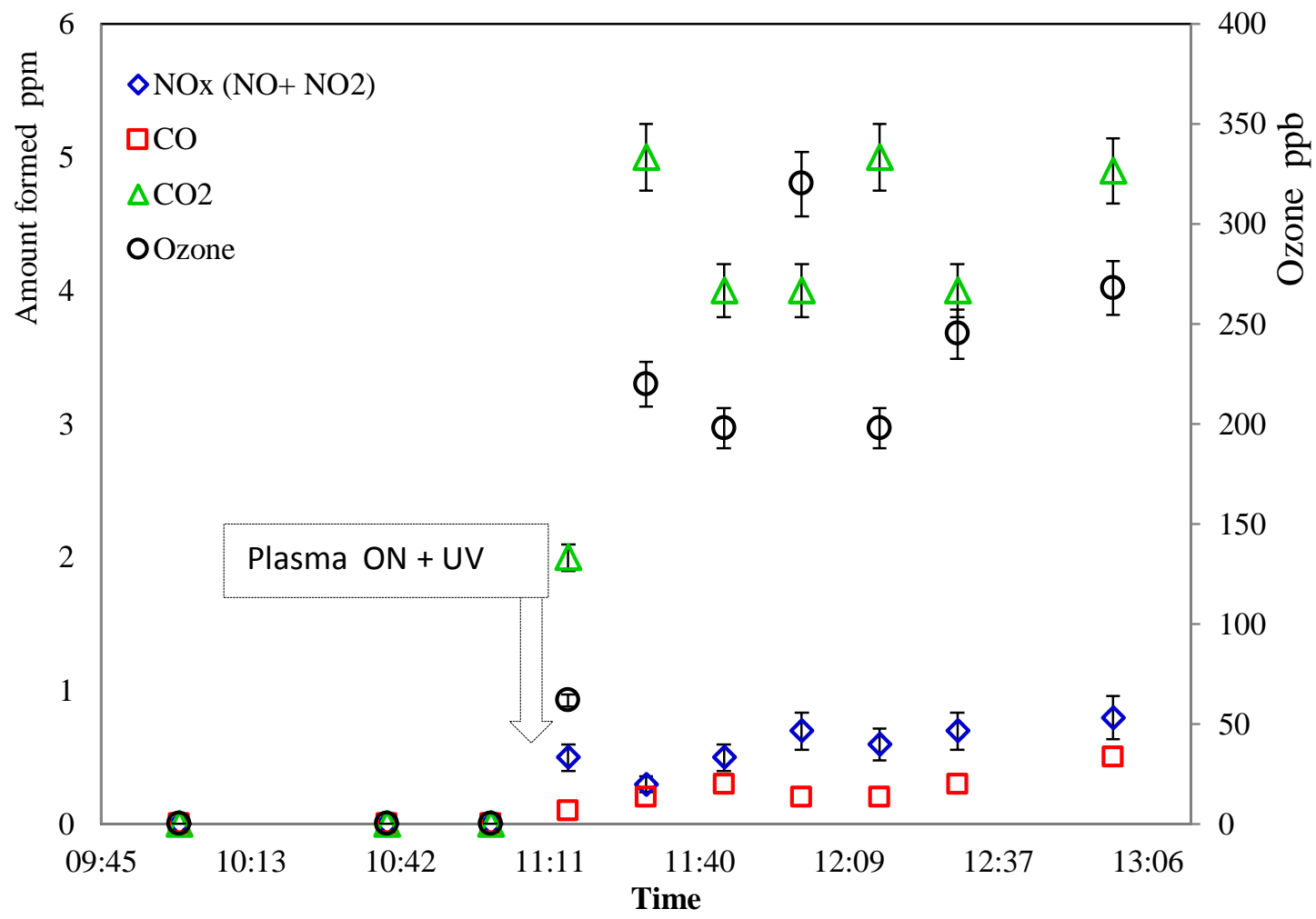

Fig. 7: temporal monitoring of inorganic by-products concentrations at downstream of the industrial reactor $\left(\right.$ Total pollution $=\sim 30 \mathrm{mg} \cdot \mathrm{m}^{-3}, \mathrm{~T}=30^{\circ} \mathrm{C}, \mathrm{RH}=53 \%, \mathrm{Q}=350 \mathrm{~m}^{3} \cdot \mathrm{h}^{-1}$ ). 
Tables:

Table 1: $\mathrm{CO}$ and $\mathrm{CO}_{2}$ selectivities and residual ozone with different processes using pilot scale

\begin{tabular}{|c|c|c|c|}
\hline & Selectivity of $\mathrm{CO}_{2}(\%)$ & Selectivity of CO (\%) & Ozone (ppm) \\
\hline Plasma & 27 & 14 & 17 \\
\hline Photocatalysis & 75 &.$<1$ &.$<1$ \\
\hline Combined process & 55 & 8 & 12 \\
\hline
\end{tabular}

